\title{
FLORÍSTICA DO BANCO DE SEMENTES DO SOLO EM ÁREAS CONTÍGUAS DE PASTAGEM DEGRADADA, PLANTIO DE EUCALIPTO E FLORESTA EM PAULA CÂNDIDO, MG
}

\author{
Sumami Rebonato Costalonga*, Geraldo Gonçalves dos Reis**, Maria das Graças Ferreira Reis**, \\ Alexandre Francisco da Silva***, Eduardo Euclydes de Lima e Borges**, \\ Felipe Pinto Guimarães**** \\ *Eng. Florestal, Mestranda em Ciência Florestal, UFV - sumami_su@yahoo.com.br \\ ** Eng. Florestal, Ph.D., Depto. de Engenharia Florestal, UFV - greis@ufv.br; mgfreis@ufv.br; elborges@ufv.br \\ ***Biólogo, Dr., Depto. de Biologia Vegetal, UFV - afsilva@ufv.br \\ ****Acadêmico de Eng. Florestal, UFV, Bolsista CNPq
}

Recebido para publicação: 13/02/2006 - Aceito para publicação: 10/07/2006

\begin{abstract}
Resumo
O banco de sementes do solo foi estudado em gradientes de cobertura vegetal tendo floresta no topo e pastagem degradada e plantio de eucalipto na encosta, em Paula Cândido (MG). As amostras foram colocadas para germinar em casa de vegetação sob 11,5 e $60 \%$ de sombreamento. As sementes germinadas de espécies herbáceas-cipó, arbustivas e arbóreas foram registradas e identificadas, sendo distribuídas em 68 espécies, 47 gêneros e 25 famílias, e as sementes germinadas de graminóides foram apenas quantificadas. Foram registradas, ao todo, 1491, 1902 e 578 sementes germinadas $/ \mathrm{m}^{2}$ na pastagem degradada, no plantio de eucalipto e na floresta, respectivamente, sendo que a maior densidade de graminóides e de arbustivas ocorreu no plantio de eucalipto, a de herbáceas-cipó ocorreu na pastagem e a de arbóreas na floresta. As famílias de herbáceas-cipó, arbustivas e arbóreas predominantes foram Rubiaceae e Lamiaceae na pastagem, Lamiaceae e Melastomataceae no plantio de eucalipto e Rubiaceae e Melastomataceae na floresta. A maioria $(59,78 \%)$ das sementes germinou sob $60 \%$ de sombreamento, sendo que 10 espécies germinaram apenas sob 11,5\% e 19 espécies apenas sob $60 \%$ de sombreamento. As espécies pioneiras corresponderam a $89 \%$ das sementes germinadas. Verificou-se maior densidade de sementes germinadas na posição inferior de amostragem no terreno.

Palavras-chave: Banco de sementes do solo; composição florística; Floresta Estacional Semidecidual Montana; pastagem degradada; plantio de eucalipto.
\end{abstract}

\begin{abstract}
Soil seed bank floristic in a contiguous area of degraded pasture, eucalypt plantation and forest. Soil samples were collected under two vegetation cover gradients with forest at the upper slope and pasture or eucalypt plantation at the intermediate and lower slope to evaluate the soil seed bank composition. Samples were placed in germination trays in greenhouses under $11.5 \%$ and $60 \%$ shading. The graminoids were only quantified and herbs-vine, shrub and trees germinated seeds were registered and identified, being distributed into 68 species, 47 genus and 25 families. It was registered 1491, 1902 and 578 germinated seeds $/ \mathrm{m}^{2}$ in the degraded pasture, eucalypt plantation and forest, respectively. Trees germinated seeds were most abundant in the forest, while shrub and graminoids were most abundant in the eucalypt plantation and, herbs and vines predominated in the pasture. The predominant families were Rubiaceae and Lamiaceae in the pasture, Lamiaceae and Melastomataceae in the eucalypt stand and Rubiaceae and Melastomataceae in the native forest. Most (59.78\%) seeds germinated under $60 \%$ shading. A total of 10 species germinated only under $11.5 \%$ shading and 19 species only under $60 \%$ shading. Pioneer species corresponded to $89 \%$ of the total shrub and trees germinated seeds. A greater number of germinated seeds were observed in the lower terrain position. Keywords: Degraded pasture; eucalypt plantation; floristic composition; Montane Semideciduous Seasonal Forest; soil seed bank.
\end{abstract}




\section{INTRODUÇÃO}

As áreas degradadas em regiões tropicais têm aumentado devido à elevada demanda por terras agricultáveis e por produtos extraídos das florestas, sendo que, na grande maioria, essas áreas entram rapidamente em degradação devido à falta de manejo adequado, especialmente no que se refere à reposição de nutrientes e intensidade de pastoreio (LUGO, 1997). A elevada demanda de áreas para atividades agropastoris gerou redução acentuada da cobertura vegetal, principalmente na área de domínio da Floresta Atlântica (FUNDAÇÃO SOS MATA ATLÂNTICA/INPE, 1993). A reposição de parte dessa vegetação é necessária para que se tenha o mínimo de cobertura exigido pela legislação.

Os fragmentos florestais remanescentes da Zona da Mata de Minas Gerais se encontram isolados e apresentam tamanho reduzido (PEREIRA et al. 2001), e a taxa de recomposição natural da vegetação em áreas anteriormente utilizadas para cultivo agrícola, pastagem ou até mesmo em áreas com florestas de espécies exóticas, a exemplo do eucalipto, depende do banco de sementes do solo e/ou da distância em relação à fonte de propágulos.

A adoção de técnicas de manejo a partir do banco de sementes do solo pode ser indicada como uma alternativa para a restauração ecológica de áreas degradadas por ação antrópica, como pastagens degradadas, áreas com florestas plantadas e fragmentos florestais degradados, que, segundo Araújo et al. (2001), é uma importante ferramenta para a recomposição da cobertura vegetal através da regeneração natural, a um custo reduzido.

Estudos sobre regeneração natural em comunidades de eucalipto têm mostrado uma diversidade de espécies relativamente elevada no seu sub-bosque, havendo variações com a espécie e a idade do povoamento de eucalipto (CALEGARIO et al. 1993; NERI et al. 2005). No entanto, estudos sobre banco de sementes do solo em plantios de eucalipto são escassos (BORGES; ENGEL, 1993). Os estudos sobre banco de sementes têm sido realizados, predominantemente, em áreas de florestas naturais (LEAL FILHO, 1992; BAIDER et al. 1999, 2001; ARAÚJO et al. 2001, 2004; FRANCO, 2005; BATISTA NETO, 2005), de pastagem (LEAL FILHO, 1992; CASTRO et al. 2003; BERTONCINI; RODRIGUES, 2003; MAIA et al. 2003, 2004) e de cultivos agrícolas (CAETANO et al. 2001; VOLL et al. 2001; LACERDA et al. 2005).

O presente estudo teve por objetivo caracterizar qualitativa e quantitativamente o banco de sementes do solo de áreas contíguas de pastagem degradada, plantio de eucalipto e floresta para identificar a possibilidade de uso desses conhecimentos em planos de manejo visando: a) regeneração natural diretamente a partir de abandono de áreas com pastagem degradada; e b) regeneração natural após o primeiro corte de florestas comerciais em pastagens degradadas.

\section{MATERIAIS E MÉTODOS}

O presente trabalho foi desenvolvido no município de Paula Cândido, Minas Gerais, localizado sob as coordenadas UTM 703600 N e 7692200 E e 704000 N e 7691600 E. O clima, segundo Köppen, é do tipo Cwb, tropical de altitude, com verões chuvosos e invernos frios e secos, temperatura média anual de $21^{\circ} \mathrm{C}$ e precipitação média anual de $1.221 \mathrm{~mm}$. Os solos da região são de baixa fertilidade, bem drenados, de elevada profundidade e muito intemperizados, sendo que as áreas de pastagens, devido ao uso intensivo e, conseqüentemente, à menor capacidade de proteção do solo, apresentam maiores riscos de serem afetados pelo processo de erosão. Esses solos são classificados como Cambissolos com feição latossólica, predominantes nas partes íngremes, onde o horizonte $\mathrm{C}$ está mais próximo à superfície, e como Latossolos Vermelho-Amarelo, com elevado teor de ferro nos topos e encostas mais suavizadas. A vegetação nativa arbórea da região é classificada como Floresta Estacional Semidecidual Montana, com inverno seco e verão chuvoso (LOUZADA, 2002).

A propriedade rural onde se desenvolveu o presente estudo possui área de aproximadamente 30,5 hectares, envolvendo 9,1 ha de pastagem contínua de Brachiaria brizantha (A. Rich.) Stapf., 5,4 ha de plantio de eucalipto (Eucalyptus grandis W. Hill ex Maiden), com nove anos de idade, oriundo de sementes e estabelecido no espaçamento de 3 × 2 m, e um fragmento de 21,5 ha de floresta, inserido em área classificada como Floresta Estacional Semidecidual Montana. Na parte central do terreno, encontrase um curso d’água com sua vegetação ciliar (brejo) ocupando uma área de aproximadamente um hectare. 
O banco de sementes do solo foi amostrado em dois gradientes de cobertura vegetal (Figura 1), ambos constituídos de floresta no terço superior da encosta e no topo. No primeiro gradiente, foi estabelecido o plantio de eucalipto na meia encosta e no terço inferior, até atingir o curso d'água; no segundo gradiente, o plantio de eucalipto foi estabelecido apenas na meia encosta, e o terço inferior, até o curso d'água, permaneceu com pastagem degradada. Foram amostrados três transectos em cada gradiente de cobertura vegetal. Cada transecto se distanciou cerca de $72 \mathrm{~m}$ um do outro em cada gradiente, seguindo o método utilizado por Louzada (2002) para a amostragem da vegetação arbórea adulta da floresta nessa mesma propriedade. Foram retiradas duas amostras de 20 x $15 \mathrm{~cm}$, na profundidade de 5 $\mathrm{cm}$, nas posições superior, média e inferior do terreno dentro de cada conjunto de cobertura vegetal, totalizando 108 amostras e uma área amostral total de 3,24 m².
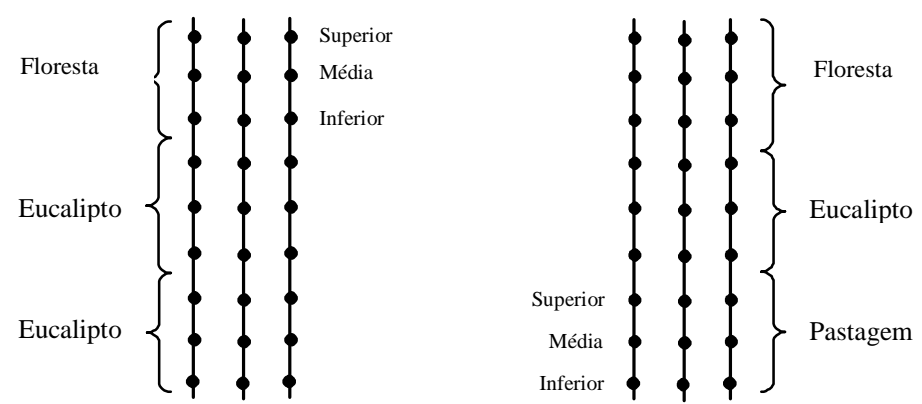

Figura 1. Esquema da amostragem do banco de sementes do solo em dois conjuntos seqüenciais de coberturas vegetais e posições relativas de amostragem no terreno dentro de cada cobertura vegetal, em Paula Cândido, MG.

Figure 1. Scheme of the seed bank data collection for two vegetation cover sequences and relative relief positions of the samples in each cover type, in the domain of the Atlantic Forest, in Paula Cândido, MG, Brazil.

As amostras de solo para o estudo do banco de sementes foram coletadas no mês de dezembro de 2004, sem a manta orgânica. Com o auxílio de uma espátula, as amostras retiradas foram colocadas em sacos plásticos de cor preta, de modo a reduzir a influência da luminosidade, sendo identificados e transportados imediatamente ao viveiro. As amostras foram colocadas em bandejas perfuradas de alumínio de $20 \times 17 \mathrm{~cm}$, com $5 \mathrm{~cm}$ de profundidade, que foram identificadas e dispostas em bancadas com aproximadamente $1 \mathrm{~m}$ de altura por $1 \mathrm{~m}$ de largura e $4 \mathrm{~m}$ de comprimento, sob dois níveis de sombreamento (11,5\% e $60 \%$ de interceptação de luz), em delineamento inteiramente casualizado. As estruturas foram totalmente cobertas para impedir a entrada de sementes. $\mathrm{O}$ sombreamento nas estruturas foi aferido utilizando-se um luxímetro. Para monitorar eventual contaminação por propágulos externos, foram colocadas três bandejas de alumínio (com as mesmas dimensões já apresentadas) contendo areia esterilizada com brometo de metila, no interior de cada estrutura. A irrigação foi realizada duas vezes ao dia, quando necessário.

Para a contagem e a identificação das plântulas emergidas das espécies presentes no banco de sementes, utilizou-se o método de germinação (GROSS, 1990) e as avaliações foram feitas em intervalos de 30 dias, durante nove meses. Após seis meses de monitoramento, o solo das bandejas foi revolvido para possibilitar que sementes mais enterradas viessem à superfície e fossem estimuladas à germinação. As plântulas que emergiam nas bandejas eram registradas, fotografadas, identificadas e removidas. Quando a identificação imediata não era possível, o exemplar era replantado em saco de polietileno contendo substrato constituído de terra de barranco, esterco e areia e mantido até ser possível sua identificação.

Os indivíduos germinados nas bandejas foram classificados em: arbóreos, arbustivos, herbáceos-cipó e graminóides. Os indivíduos graminóides, aqui caracterizados como todas as plantas com o aspecto de uma gramínea, foram contados e descartados. As sementes germinadas das demais espécies herbáceas (incluindo cipós), e das espécies arbustivas e arbóreas foram contadas e identificadas. As espécies arbustivo-arbóreas foram classificadas em grupos ecológicos de acordo com o sistema de Budowski (1965), tendo sido consultados os trabalhos de Baider et al. (1999), Pezzopane (2001), Higuchi (2003), Silva et al. (2003), Silva et al. (2004), Franco (2005) e Batista Neto (2005), que também utilizaram essa classificação. 


\section{RESULTADOS E DISCUSSÃO}

A composição florística das plantas herbáceas, arbustivas e arbóreas na pastagem, plantio de eucalipto e floresta foi composta por 68 espécies, 47 gêneros e 25 famílias. Três espécies foram identificadas até família, cinco até gênero e duas permaneceram sem identificação (Tabela 1).

Na pastagem, as famílias mais representativas no banco de sementes do solo foram Rubiaceae (26,9\% do total de sementes germinadas), Lamiaceae (21,7\%) e Oxalidaceae (17,9\%), constituídas por espécies herbáceas, destacando-se Diodia teres Walter (20,6\%), Oxalis corniculata L. (17,6\%), Hyptis atrorubens Poit. (12,2\%) e Thelypteris dentata (Forssk) E. P. St. John. (9,7\%). No plantio de eucalipto, predominaram as famílias Lamiaceae (26,9\% do total de sementes germinadas), Melastomataceae (23,8\%) e Rubiaceae (17,9\%). As espécies que se destacaram foram H. atrorubens (25,9\%), Leandra purpurascens Cogn. (14,5\%) e D. teres $(7,7 \%)$. Na floresta, houve predomínio de Rubiaceae (30\% do total de sementes germinadas), com elevada participação de Spermacoce verticillata L., Melastomataceae (22,2\%), sendo espécies mais representativas $L$. purpurascens (8,3\%) e Miconia sp (5,9\%), e Cecropiaceae (13,4\%), com as espécies Cecropia glaziovii Snethl. (6,7\%) e Cecropia. hololeuca Miq (6,7\%) (Tabela 1, Figura 2).

Tabela 1. Relação de espécies em ordem alfabética por família e gênero, e número de sementes germinadas em viveiro, por espécie - classificadas em herbácea (her), arbustiva (arb), arbórea (a) e cipó (c) - e por grupo ecológico (GE) - classificados em pioneira (P) e secundária inicial (SI) -, sob 11,5 e $60 \%$ de sombreamento, do banco de sementes do solo de pastagem degradada, plantio de eucalipto e floresta, em Paula Cândido, MG.

Table 1. Floristic composition of adult tree species, classified as herbs (her), shrubs (arb), trees (a) and liana (c), with its corresponding ecological group (GE) (PI - pioneer, SI - initial secondary) and number of germinated seeds $/ \mathrm{m}^{2}$ under 11.5 and $60 \%$ shading, of degraded pasture, eucalypt plantation and forest soil seed bank, in the domain of the Atlantic Forest, in Paula Cândido, MG, Brazil.

\begin{tabular}{|c|c|c|c|c|c|c|c|c|c|}
\hline \multirow{2}{*}{ Família e Espécie } & \multirow{2}{*}{ Nome vulgar } & \multirow{2}{*}{$\mathbf{H}$} & \multirow{2}{*}{ GE } & \multicolumn{2}{|c|}{ Pastagem } & \multicolumn{2}{|c|}{ Eucalipto } & \multicolumn{2}{|c|}{ Floresta } \\
\hline & & & & 1 & 2 & 1 & 2 & 1 & 2 \\
\hline \multicolumn{10}{|l|}{ ASTERACEAE } \\
\hline $\begin{array}{l}\text { Acanthospermum australe (Loefl.) } \\
\quad \text { Kuntze }\end{array}$ & mata pasto & her & - & 3,70 & 0,00 & 0,00 & 0,00 & 0,00 & 0,00 \\
\hline Ageratum conyzoides L. & mentrasto & her & - & 0,00 & 0,00 & 1,23 & 1,23 & 0,00 & 0,00 \\
\hline Baccharis racunculifolia DC. & alecrim & arb & $\mathrm{P}$ & 3,70 & 0,00 & 6,17 & 9,88 & 0,00 & 0,00 \\
\hline Baccharis trimera (Less) DC. & carqueja & her & - & 0,00 & 0,00 & 0,00 & 8,64 & 0,00 & 0,00 \\
\hline Bidens sp. & picão & her & - & 66,67 & 0,00 & 3,70 & 0,00 & 0,00 & 0,00 \\
\hline Conyza bonariensis (L.) Cronquist & buva & her & - & 7,41 & 7,41 & 2,47 & 12,35 & 0,00 & 9,26 \\
\hline $\begin{array}{l}\text { Erechtiles hieraciifolius (L.) Raf. } \\
\quad \text { ex DC. }\end{array}$ & serralha-brava & her & - & 3,70 & 0,00 & 0,00 & 2,47 & 0,00 & 0,00 \\
\hline Chaptalia nutans (L.) Polak & língua-de-vaca & her & - & 0,00 & 0,00 & 0,00 & 3,70 & 0,00 & 3,70 \\
\hline Gnaphalium purpureum L. & macela & her & - & 0,00 & 3,70 & 3,70 & 4,94 & 0,00 & 0,00 \\
\hline Gnaphalium spicatum Lam. & macela & her & - & 3,70 & 0,00 & 3,70 & 3,70 & 0,00 & 0,00 \\
\hline Vernonia condensata Baker & boldo-da-índia & arb & $\mathrm{P}$ & 0,00 & 0,00 & 0,00 & 0,00 & 3,70 & 1,85 \\
\hline Vernonia polyanthes Less. & assa-peixe & a & $\mathrm{P}$ & 0,00 & 0,00 & 0,00 & 4,94 & 0,00 & 1,85 \\
\hline \multicolumn{10}{|l|}{ BRASSICACEAE } \\
\hline Cardamine bonariensis Pers. & agrião-bravo & her & - & 11,11 & 81,48 & 2,47 & 2,47 & 0,00 & 0,00 \\
\hline \multicolumn{10}{|l|}{ CECROPIACEAE } \\
\hline Cecropia hololeuca Miq & $\begin{array}{l}\text { embaúba- } \\
\text { branca }\end{array}$ & $\mathrm{a}$ & $\mathrm{P}$ & 0,00 & 0,00 & 6,17 & 6,17 & 14,81 & 25,93 \\
\hline Cecropia glaziovi Snethl. & embaúba & a & $\mathrm{P}$ & 0,00 & 0,00 & 6,17 & 2,47 & 35,19 & 5,56 \\
\hline \multicolumn{10}{|l|}{ CLUSIACEAE } \\
\hline Vismia martiana (Aubl.) Reichardt & ruão & $\mathrm{a}$ & $\mathrm{P}$ & 0,00 & 3,70 & 0,00 & 40,74 & 5,56 & 12,96 \\
\hline
\end{tabular}




\begin{tabular}{|c|c|c|c|c|c|c|c|c|c|}
\hline \multirow{2}{*}{ Família e Espécie } & \multirow{2}{*}{ Nome vulgar } & \multirow{2}{*}{$\mathbf{H}$} & \multirow{2}{*}{ GE } & \multicolumn{2}{|c|}{ Pastagem } & \multicolumn{2}{|c|}{ Eucalipto } & \multicolumn{2}{|c|}{ Floresta } \\
\hline & & & & 1 & 2 & 1 & 2 & 1 & 2 \\
\hline \multicolumn{10}{|l|}{ COMMELINACEAE } \\
\hline Commelina benghalensis L. & comelina & her & - & 0,00 & 0,00 & 0,00 & 2,47 & 0,00 & 0,00 \\
\hline DILLENIACEAE & & & - & & & & & & \\
\hline Davilla rugosa Poir. & cipó-caboclo & c & - & 0,00 & 0,00 & 0,00 & 0,00 & 0,00 & 1,85 \\
\hline EUPHORBIACEAE & & & - & & & & & & \\
\hline Alchornea glandulosa Poepp. \& Endl. & casca-doce & $\mathrm{a}$ & $\mathrm{P}$ & 0,00 & 0,00 & 0,00 & 2,47 & 0,00 & 1,85 \\
\hline Chamaesyce hirta (L.) Millsp. & $\begin{array}{l}\text { erva-de-santa- } \\
\text { luzia }\end{array}$ & her & - & 0,00 & 3,70 & 0,00 & 0,00 & 0,00 & 0,00 \\
\hline Maprounea guianensis Aubl. & maprônia & a & $\mathrm{P}$ & 0,00 & 0,00 & 0,00 & 0,00 & 0,00 & 1,85 \\
\hline Phyllanthus tenellus Roxb. & quebra-pedra & her & - & 0,00 & 0,00 & 1,23 & 3,70 & 0,00 & 1,85 \\
\hline \multicolumn{10}{|l|}{ FLACOURTIACEAE } \\
\hline Casearia aculeata Jacq. & espeto-branco & a & SI & 0,00 & 0,00 & 1,23 & 0,00 & 1,85 & 0,00 \\
\hline \multicolumn{10}{|l|}{ LAMIACEAE } \\
\hline Hyptis atrorubens Poit. & mentinha & her & - & 148,15 & 114,81 & 140,74 & 380,25 & 0,00 & 7,41 \\
\hline Hyptis mutabilis (Rich.) Briq. & cheirosa & her & - & 100,00 & 85,19 & 3,70 & 11,11 & 0,00 & 0,00 \\
\hline Hyptis pectinata (L.) Poit. & hortelã-gigante & her & - & 0,00 & 0,00 & 6,17 & 0,00 & 0,00 & 0,00 \\
\hline $\begin{array}{l}\text { Marsypianthes chamaedrys (Vahl) } \\
\text { Kuntze }\end{array}$ & $\begin{array}{l}\text { coração-de- } \\
\text { frade }\end{array}$ & her & - & 0,00 & 3,70 & 0,00 & 0,00 & 0,00 & 0,00 \\
\hline Lamiaceae 1 & & her & - & 0,00 & 11,11 & 0,00 & 0,00 & 0,00 & 0,00 \\
\hline \multicolumn{10}{|l|}{ LEG. CAESALPINOIDEAE } \\
\hline $\begin{array}{l}\text { Chamaecrista rotundifolia (Pers.) } \\
\text { Greene }\end{array}$ & $\begin{array}{l}\text { erva-de- } \\
\text { coração }\end{array}$ & her & - & 3,70 & 3,70 & 0,00 & 0,00 & 0,00 & 0,00 \\
\hline \multicolumn{10}{|l|}{ LEG. MIMOSOIDEAE } \\
\hline Aeschynomene histrix Poir. & dormideira & her & - & 3,70 & 3,70 & 0,00 & 0,00 & 0,00 & 0,00 \\
\hline Plathymenia foliolosa Benth. & vinhático & $\mathrm{a}$ & SI & 0,00 & 0,00 & 0,00 & 0,00 & 1,85 & 0,00 \\
\hline \multicolumn{10}{|l|}{ LEG. PAPILIONOIDEAE } \\
\hline Desmodium adscendens (Sw.) DC. & carrapicho & her & - & 0,00 & 3,70 & 0,00 & 0,00 & 0,00 & 0,00 \\
\hline $\begin{array}{l}\text { Glycine wightii (Wight e Arn.) } \\
\text { Verdc. }\end{array}$ & soja-perene & her & - & 3,70 & 3,70 & 0,00 & 0,00 & 0,00 & 0,00 \\
\hline Mimosa pudica L. & dormideira & her & - & 0,00 & 0,00 & 0,00 & 0,00 & 0,00 & 0,00 \\
\hline \multicolumn{10}{|l|}{ LYTHRACEAE } \\
\hline $\begin{array}{l}\text { Cuphea carthagenensis (Jacq.) J.F. } \\
\text { Macbr. }\end{array}$ & sete-sangrias & her & - & 7,41 & 22,22 & 0,00 & 20,99 & 0,00 & 0,00 \\
\hline \multicolumn{10}{|l|}{ MALVACEAE } \\
\hline Sida cordifolia L. & malva-branca & her & - & 3,70 & 0,00 & 2,47 & 0,00 & 0,00 & 0,00 \\
\hline Sida glaziovii K. Schum. & $\begin{array}{l}\text { guaxuma- } \\
\text { branca }\end{array}$ & her & - & 14,81 & 3,70 & 44,44 & 24,69 & 12,96 & 1,85 \\
\hline Sida rhombifolia L. & guaxuma & her & - & 3,70 & 3,70 & 2,47 & 2,47 & 0,00 & 14,81 \\
\hline Sida urens L. & $\begin{array}{l}\text { guaxuma- } \\
\text { dourada }\end{array}$ & her & - & 0,00 & 3,70 & 1,23 & 0,00 & 0,00 & 0,00 \\
\hline $\begin{array}{l}\text { Sidastrum micranthum (St. Hilaire) } \\
\text { Fryxell }\end{array}$ & malvisco & her & - & 0,00 & 7,41 & 0,00 & 0,00 & 0,00 & 0,00 \\
\hline \multicolumn{10}{|l|}{ MELASTOMATACEAE } \\
\hline Leandra purpuracens Cogn. & apaga-fogo & arb & $\mathrm{P}$ & 29,63 & 48,15 & 123,46 & 241,98 & 16,67 & 33,33 \\
\hline Miconia sp. & & $\mathrm{a}$ & $\mathrm{P}$ & 0,00 & 0,00 & 0,00 & 0,00 & 11,11 & 24,07 \\
\hline Miconia cinnamomifolia Naudin & quaresminha & $\mathrm{a}$ & $\mathrm{P}$ & 0,00 & 0,00 & 0,00 & 2,47 & 18,52 & 5,56 \\
\hline Tibouchina sp. & & arb & $\mathrm{P}$ & 3,70 & 11,11 & 62,96 & 38,27 & 5,56 & 7,41 \\
\hline Melastomataceae 4 & & arb & $\mathrm{P}$ & 0,00 & 0,00 & 0,00 & 0,00 & 0,00 & 1,85 \\
\hline Tibouchina sp. 2 & & arb & $\mathrm{P}$ & 0,00 & 0,00 & 0,00 & 0,00 & 1,85 & 0,00 \\
\hline Melastomataceae 2 & & arb & $\mathrm{P}$ & 0,00 & 0,00 & 0,00 & 11,11 & 0,00 & 5,56 \\
\hline Melastomataceae 7 & & arb & $\mathrm{P}$ & 0,00 & 0,00 & 0,00 & 0,00 & 0,00 & 3,70 \\
\hline
\end{tabular}

FLORESTA, Curitiba, PR, v. 36, n. 2, mai./ago. 2006. 


\begin{tabular}{|c|c|c|c|c|c|c|c|c|c|}
\hline \multirow{2}{*}{ Família e Espécie } & \multirow{2}{*}{ Nome vulgar } & \multirow{2}{*}{$\mathbf{H}$} & \multirow{2}{*}{ GE } & \multicolumn{2}{|c|}{ Pastagem } & \multicolumn{2}{|c|}{ Eucalipto } & \multicolumn{2}{|c|}{ Floresta } \\
\hline & & & & 1 & 2 & 1 & 2 & 1 & 2 \\
\hline \multicolumn{10}{|l|}{ OXALIDACEAE } \\
\hline Oxalis corniculata L. & trevo & her & - & 14,81 & 366,67 & 27,16 & 66,67 & 0,00 & 14,81 \\
\hline \multicolumn{10}{|l|}{ PIPERACEAE } \\
\hline Piper sp. & piper & arb & $\mathrm{P}$ & 0,00 & 3,70 & 0,00 & 1,23 & 18,52 & 5,56 \\
\hline Pothomorphe umbellata (L.) Miq. & & arb & SI & 0,00 & 0,00 & 1,23 & 7,41 & 0,00 & 3,70 \\
\hline \multicolumn{10}{|l|}{ RUBIACEAE } \\
\hline Diodia alata Nees \& Mart. & poia-do-brejo & her & - & 14,81 & 14,81 & 0,00 & 50,62 & 0,00 & 0,00 \\
\hline Diodia teres Walter & mata-pasto & her & - & 207,41 & 237,04 & 88,89 & 66,67 & 0,00 & 0,00 \\
\hline Richardia brasiliensis Gomes & poia-branca & her & - & 3,70 & 7,41 & 0,00 & 2,47 & 0,00 & 0,00 \\
\hline Spermacoce latifolia Aubl. & erva-quente & her & - & 7,41 & 3,70 & 91,36 & 0,00 & 3,70 & 9,26 \\
\hline Spermacoce verticillata $\mathrm{L}$. & cordão-de-frade & her & - & 0,00 & 77,78 & 54,32 & 4,94 & 187,04 & 0,00 \\
\hline \multicolumn{10}{|l|}{ RUTACEAE } \\
\hline Dictyoloma vandellianum A. Juss. & brauninha & $\mathrm{a}$ & SI & 0,00 & 0,00 & 0,00 & 0,00 & 3,70 & 0,00 \\
\hline SCROPHULARIACEAE & & & & 0,00 & 0,00 & 0,00 & 0,00 & 0,00 & 0,00 \\
\hline Scoparia dulcis L. & vassourinha & her & - & 0,00 & 3,70 & 8,64 & 18,52 & 0,00 & 0,00 \\
\hline SOLANACEAE & & & & 0,00 & 0,00 & 0,00 & 0,00 & 0,00 & 0,00 \\
\hline Solanum capsicoides All. & juá-marelo & her & - & 0,00 & 0,00 & 1,23 & 0,00 & 0,00 & 0,00 \\
\hline Solanum cernuum Vell. & braço-de-mono & arb & $\mathrm{P}$ & 0,00 & 0,00 & 0,00 & 1,23 & 0,00 & 0,00 \\
\hline Solanum americanum Mill. & maria-preta & her & - & 0,00 & 0,00 & 1,23 & 0,00 & 0,00 & 0,00 \\
\hline \multicolumn{10}{|l|}{ THELYPTERIDACEAE } \\
\hline $\begin{array}{l}\text { Thelypteris dentata (Forssk) E. P. } \\
\text { St. John. }\end{array}$ & samambaia & her & - & 55,56 & 151,85 & 4,94 & 30,86 & 0,00 & 1,85 \\
\hline TILIACEAE & & & & 0,00 & 0,00 & 0,00 & 0,00 & 0,00 & 0,00 \\
\hline Corchorus olitorius L. & melouquiá & her & - & 0,00 & 14,81 & 0,00 & 0,00 & 0,00 & 0,00 \\
\hline Triunfetta bartramia L. & carrapichão & her & - & 3,70 & 0,00 & 3,70 & 0,00 & 0,00 & 0,00 \\
\hline \multicolumn{10}{|l|}{ UMBELLIFERAE } \\
\hline Centella asiatica (L.) Urb. & pata-de-cavalo & her & - & 14,81 & 29,63 & 30,86 & 39,51 & 0,00 & 0,00 \\
\hline \multicolumn{10}{|l|}{ URTICACEAE } \\
\hline Pilea microphylla Liebm. & piléia & her & - & 11,11 & 18,52 & 6,17 & 75,31 & 0,00 & 0,00 \\
\hline Não identificada 1 & & arb & $\mathrm{P}$ & 3,70 & 3,70 & 8,64 & 19,75 & 9,26 & 16,67 \\
\hline Não identificada 2 & & her & - & 0,00 & 3,70 & 0,00 & 0,00 & 0,00 & 3,70 \\
\hline Total & & & & 759,26 & 1366,67 & 754,32 & 1230,86 & 351,85 & 229,63 \\
\hline
\end{tabular}

No banco de sementes do solo da pastagem degradada foram registradas 1491 sementes germinadas $/ \mathrm{m}^{2}$, sendo 428 de graminóides, 1007 de herbáceas-cipó, 54 de arbustivas e 2 de arbóreas. No plantio de eucalipto foram registradas 1902 sementes germinadas $/ \mathrm{m}^{2}$, sendo 909 de graminóides, 690 de herbáceas-cipó, 267 de arbustivas e 36 de arbóreas. Na floresta foram registradas 578 sementes germinadas $/ \mathrm{m}^{2}$, sendo 287 de graminóides, 137 de herbáceas-cipó, 68 de arbustivas e 86 de arbóreas. Foi registrada apenas uma semente de cipó germinada, proveniente do banco de sementes da floresta.

Pode-se depreender que a capacidade de regeneração natural do componente arbóreo a partir da pastagem degradada estudada é bem menor que no plantio de eucalipto ou no fragmento florestal degradado, em razão do reduzido número de espécies e de indivíduos arbustivos e arbóreos. Dessa forma, a recomposição da vegetação arbórea a partir de áreas de pastagens degradadas na Zona da Mata de Minas Gerais exige manejo específico com adição de propágulos, principalmente de pioneiras, para enriquecimento do banco de sementes do solo, ou através de plantio de espécies arbóreas dos diferentes estádios sucessionais iniciais. Esse plantio de espécies arbóreas pode se constituir de um povoamento comercial puro, inclusive com eucalipto, que pode ser explorado em um ou dois cortes, com posterior abandono da área para permitir a regeneração a partir do estoque de sementes do solo. Em povoamentos manejados para uso múltiplo, em ciclos longos, há, também, o favorecimento da regeneração natural no 
sub-bosque (CALEGÁRIO et al. 1993; NERI et al. 2005), cujas espécies são importantes como fonte de alimento e abrigo para os dispersores. Espécies arbustivas e arbóreas, nativas ou exóticas, constituem-se em "poleiros" para dispersores de sementes, aumentando, assim, a possibilidade de enriquecimento do banco de sementes no solo com espécies arbóreas. Neri et al. (2005) observaram redução da riqueza e densidade de espécies arbóreas anemocóricas, da borda para o interior de um plantio de eucalipto, a partir de um fragmento de vegetação de cerrado, tendo ocorrido aumento da percentagem de indivíduos zoocóricos no interior do talhão. O enriquecimento do banco de sementes em povoamentos de florestas comerciais depende, dentre outros fatores, da distância dos mesmos em relação ao fragmento de floresta nativa (BORGES; ENGEL, 1993).
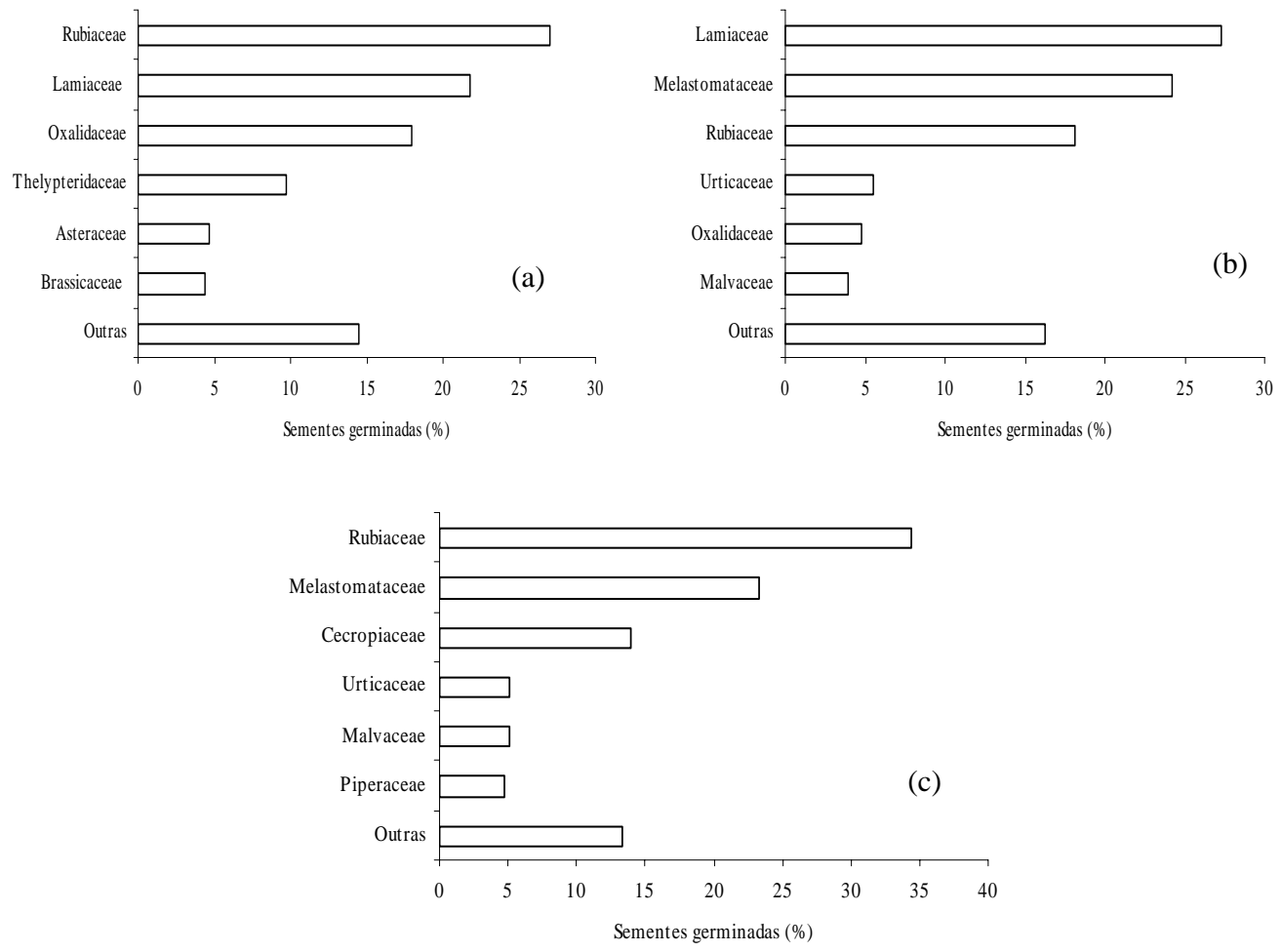

Figura 2. Famílias mais representativas com base na percentagem de sementes germinadas, no banco de sementes do solo na pastagem degradada (a), no plantio de eucalipto (b) e na floresta (c), em Paula Cândido, MG.

Figure 2. Most representative families based on the percentage of germinated seeds of degraded pasture, eucalypt plantation and forest soil seed bank, in the domain of the Atlantic Forest, in Paula Cândido, MG, Brazil

No banco de sementes do solo da pastagem degradada foram registradas 1491 sementes germinadas $/ \mathrm{m}^{2}$, sendo 428 de graminóides, 1007 de herbáceas-cipó, 54 de arbustivas e 2 de arbóreas. No plantio de eucalipto foram registradas 1902 sementes germinadas $/ \mathrm{m}^{2}$, sendo 909 de graminóides, 690 de herbáceas-cipó, 267 de arbustivas e 36 de arbóreas. Na floresta foram registradas 578 sementes germinadas $/ \mathrm{m}^{2}$, sendo 287 de graminóides, 137 de herbáceas-cipó, 68 de arbustivas e 86 de arbóreas. Foi registrada apenas uma semente de cipó germinada, proveniente do banco de sementes da floresta.

Pode-se depreender que a capacidade de regeneração natural do componente arbóreo a partir da pastagem degradada estudada é bem menor que no plantio de eucalipto ou no fragmento florestal degradado, em razão do reduzido número de espécies e de indivíduos arbustivos e arbóreos. Dessa forma, a recomposição da vegetação arbórea a partir de áreas de pastagens degradadas na Zona da Mata de Minas Gerais exige manejo específico com adição de propágulos, principalmente de pioneiras, para enriquecimento do banco de sementes do solo, ou através de plantio de espécies arbóreas dos diferentes 
estádios sucessionais iniciais. Esse plantio de espécies arbóreas pode se constituir de um povoamento comercial puro, inclusive com eucalipto, que pode ser explorado em um ou dois cortes, com posterior abandono da área para permitir a regeneração a partir do estoque de sementes do solo. Em povoamentos manejados para uso múltiplo, em ciclos longos, há, também, o favorecimento da regeneração natural no sub-bosque (CALEGÁRIO et al. 1993; NERI et al. 2005), cujas espécies são importantes como fonte de alimento e abrigo para os dispersores. Espécies arbustivas e arbóreas, nativas ou exóticas, constituem-se em "poleiros" para dispersores de sementes, aumentando, assim, a possibilidade de enriquecimento do banco de sementes no solo com espécies arbóreas. Neri et al. (2005) observaram redução da riqueza e densidade de espécies arbóreas anemocóricas, da borda para o interior de um plantio de eucalipto, a partir de um fragmento de vegetação de cerrado, tendo ocorrido aumento da percentagem de indivíduos zoocóricos no interior do talhão. O enriquecimento do banco de sementes em povoamentos de florestas comerciais depende, dentre outros fatores, da distância dos mesmos em relação ao fragmento de floresta nativa (BORGES; ENGEL, 1993).

Em trabalhos desenvolvidos na região do presente estudo, foram encontrados os seguintes valores de densidade de sementes germinadas por metro quadrado: a) 949 sementes germinadas $/ \mathrm{m}^{2} \mathrm{em}$ floresta secundária, sendo 286 graminóides, 277 herbáceas-cipós e 386 arbustivo-arbóreas, em amostragem realizada ao final da estação chuvosa, sendo esses valores correspondentes a 982, 220, 258 e 512, respectivamente, para amostragem realizada ao final da estação seca (BATISTA NETO, 2005); b) 1039 sementes germinadas $/ \mathrm{m}^{2}$ em floresta secundária, sendo 33 cipós e espécies não identificadas, 228 graminóides e herbáceas, 234 arbustivas e 545 arbóreas (FRANCO, 2005); c) 1346 sementes germinadas $/ \mathrm{m}^{2}$, sendo 1035 graminóides e herbáceas e 311 arbustivo-arbóreas (SOUZA et al. 2006). Leal Filho (1992), estudando vegetação em diferentes estádios sucessionais, encontrou valores de densidade baixos, tendo registrado 413 sementes germinadas $/ \mathrm{m}^{2}$ na pastagem, sendo 308 graminóides e 105 arbustivo-arbóreas; 369,04 sementes germinadas $/ \mathrm{m}^{2}$ na capoeira, sendo 187 graminóides e 187 arbustivoarbóreas; e 189 sementes germinadas $/ \mathrm{m}^{2}$ na floresta secundária madura em topo de morro, sendo 64 graminóides e 125 arbustivo-arbóreas.

A densidade de sementes germinadas $/ \mathrm{m}^{2}$ para a floresta no presente estudo é inferior à obtida por Batista Neto (2005), Franco (2005) e Souza et al. (2006), porém bem superior ao observado por Leal Filho (1992). A densidade obtida para a pastagem degradada no presente estudo é, também, muito superior ao observado por Leal Filho (1992), porém, bem inferior ao observado por Maia et al. (2003). As diferenças na densidade de sementes podem ser devido ao tamanho da amostra e época do ano em que foi realizada a amostragem, bem como ao estádio de sucessão e de degradação da área estudada, a posição topográfica e a declividade do terreno em que foi realizada a amostragem, dentre outros aspectos. Usualmente, a maioria dos trabalhos envolve uma única coleta por ano, e as sementes de algumas espécies podem ter germinado ou se deteriorado até o momento da amostragem. No presente estudo, a área de floresta se encontrava na porção superior da encosta e no topo, enquanto que no trabalho de Batista Neto (2005) foram coletadas amostras em dez sítios com diferenças em declividade, posição topográfica, exposição e estádio seral.

De modo geral, as espécies herbáceas predominaram no banco de sementes do solo das três coberturas vegetais do estudo, o que, também, foi observado por Souza et al. (2006), porém observa-se redução substancial na densidade de herbáceas no sentido: pastagem natural > eucalipto > floresta. As espécies herbáceas encontradas no presente estudo também foram encontradas por outros autores em trabalhos realizados na região (SOUZA et al. 2006; FRANCO, 2005), indicando que são bem adaptadas àquele sítio, independentemente da cobertura vegetal predominante a que elas se encontram associadas.

As espécies arbustivo-arbóreas representaram apenas $12,67 \%$ dos indivíduos registrados no banco de sementes do solo, sendo que as de porte arbustivo $(9,31 \%)$ predominaram em relação às de porte arbóreo, com exceção da floresta, onde o hábito arbóreo foi predominante, principalmente com indivíduos pertencentes às famílias Melastomataceae e Cecropiaceae (Tabela 1). Nas coberturas vegetais estudadas, a família Melastomataceae ocupou o primeiro lugar das famílias mais representativas de hábito arbustivoarbóreo. Essa família é muito importante nos ecossistemas tropicais, onde se encontram cerca de 3.000 espécies, principalmente dos gêneros Leandra, Miconia e Tibouchina, comuns nas regiões Oeste, Sudeste e Sul do Brasil (GOLDENBERGER; VARASSIN, 2001).

As espécies arbustivo-arbóreas no banco de sementes do solo na pastagem pertencem apenas às pioneiras (100\% do total de espécies). No plantio de eucalipto, esse valor foi de $86,6 \%$, e na floresta, de 
80,8\%, não tendo sido encontradas espécies secundárias tardias. Na composição florística da vegetação arbórea adulta no mesmo fragmento florestal em que foi realizada a amostragem do banco de sementes do solo, há também predomínio de espécies pioneiras (35\%) e secundárias iniciais (40\%) (LOUZADA, 2002). Esses resultados evidenciam que o banco de sementes do solo contribui principalmente para a regeneração das espécies dos estádios iniciais de sucessão de áreas alteradas natural ou antropicamente, havendo, porém, restrições às espécies de grupos sucessionais mais avançados. Para acelerar o processo de sucessão ecológica, há necessidade, então, de se adotarem plantios de enriquecimento com espécies das categorias secundárias iniciais e tardias, uma vez que esses grupos ecológicos têm pouca representatividade no depósito de sementes no solo nesse tipo de cobertura vegetal.

A regeneração natural na Floresta Atlântica pode ser descrita por uma seqüência de estádios dominados, inicialmente, por herbáceas, seguidas por arbustos e árvores pioneiras, as quais parecem imprescindíveis ao estabelecimento de árvores e arbustos que compõem a floresta madura (BAIDER et al. 2001). As sementes de espécies herbáceas espontâneas, como as registradas neste trabalho, têm a função de iniciar a ocupação dos espaços abertos na comunidade de plantas, reiniciando o processo de sucessão, atuando desde os primeiros estágios de colonização do ambiente alterado (ARAÚJO et al. 2004). Porém, vale salientar que esse processo inicial de sucessão é lento, uma vez que as plantas herbáceas em uma sucessão secundária dificultam o estabelecimento de espécies arbustivas e arbóreas. Há, assim, necessidade de se ter maior densidade de sementes arbustivas e arbóreas para aumentar as chances de seu estabelecimento, uma vez que são importantes para dar início à formação das ilhas de vegetação.

De maneira geral, $59,78 \%$ das sementes germinaram sob o nível de sombreamento de $60 \%$ (Tabela 2), indicando que o sombreamento mais intenso foi mais favorável à germinação das sementes existentes no banco de semente do solo. As sementes de graminóides e herbáceas-cipó da pastagem e do plantio de eucalipto germinaram predominantemente sob $60 \%$ de sombreamento, enquanto aquelas da floresta predominaram sob 11,5\% de sombreamento, principalmente em razão da ocorrência de número muito elevado de sementes de $S$. verticillata nesse ambiente. A germinação de sementes de espécies arbustivas e arbóreas foi substancialmente mais elevada sob o nível de sombreamento de $60 \%$.

Tabela 2. Número médio de sementes germinadas $/ \mathrm{m}^{2}$, em banco de sementes do solo de pastagem degradada, plantio de eucalipto e floresta, por hábito de vida, sob 11,5 e $60 \%$ de sombreamento, em Paula Cândido, MG.

Table 2. Average number of germinated seeds $/ \mathrm{m}^{2}$, of degraded pasture, eucalypt plantation and forest soil seed bank, for each plant habit, under 11.5 and $60 \%$ shade, in the domain of the Atlantic Forest, in Paula Cândido, MG, Brazil.

\begin{tabular}{lccrrrrrr}
\hline \multirow{2}{*}{ Hábito } & \multicolumn{3}{c}{ NS 11,5 \% } & & \multicolumn{3}{c}{ NS 60 \% } \\
\cline { 2 - 3 } \cline { 7 - 8 } & Pastagem & Eucalipto & Floresta & & Pastagem & Eucalipto & Floresta \\
\hline Graminóide & 396,30 & 748,15 & 325,93 & & 459,26 & 1070,37 & 248,15 \\
Herbáceo-cipó & 718,52 & 538,27 & 203,70 & & 1296,30 & 840,74 & 70,37 \\
Arbustivo & 40,74 & 202,47 & 55,56 & & 66,67 & 330,86 & 79,63 \\
Arbóreo & 0,00 & 13,58 & 92,59 & & 3,70 & 59,26 & 79,63 \\
\hline Total & 1155,56 & 1502,47 & 677,78 & & 1825,93 & 2301,23 & 477,78 \\
\hline
\end{tabular}

NS = níveis de sombreamento de $11,5 \%$ e $60 \%$.

Apesar de se ter informações na literatura de que a germinação ocorre a partir de estímulos da luz e da elevação térmica, temos observado que algumas espécies têm germinado apenas ou predominantemente sob $60 \%$ de sombreamento. No presente trabalho, 19 espécies germinaram apenas quando sob $60 \%$ de sombreamento, sendo que Bacharis trimera (Less) DC. apresentou sete sementes germinadas e Chaptalia nutans (1.) Polak e Vernonia polyanthes Less. apresentaram, cada uma, cinco sementes germinadas. É interessante destacar que Coniza bonariensis (L.) Cronquist (total de 21 sementes germinadas), Cardamine bonariensis Pers. (29), Vismia martiana (Aubl.) Reichardt (41), Cuphea carthagenensis (Jacq.) J. F. Macbr. (25), Sida rhombifolia L. (14), Pothomorphe umbellata (L.) Miq. (8), Diodia alata Nees \& Mart. (49) e Pilea microphylla Liebm. (74) tiveram mais de $80 \%$ das sementes germinadas sob $60 \%$ de sombreamento, justificando, assim, o uso de sombreamento para favorecer a germinação das sementes dessas espécies. Também foi observado que 10 espécies germinaram apenas 
sob 11,5\% de sombreamento, destacando-se Bidens sp, que apresentou 21 indivíduos germinados. As demais espécies que germinaram apenas sob $11,5 \%$ de sombreamento tiveram menos de três sementes germinadas, e apenas $S$. verticillata teve sementes germinadas nos dois ambientes, porém com mais de $80 \%$ das sementes germinadas em ambiente menos sombreado. Batista Neto (2005) também observou que um maior número de espécies arbustivo-arbóreas germinaram apenas sob $60 \%$ de sombreamento enquanto apenas duas germinaram apenas sob $11,5 \%$ de sombreamento. Essas diferenças na germinação de sementes podem estar associadas a variações nas exigências lumínicas intrínsecas a cada espécie (BATISTA NETO, 2005), bem como pelo fato de se ter no ambiente mais sombreado um elevado nível de umidade no solo, o que favorece a germinação (FRANCO, 2005).

Considerando todos os tipos de cobertura vegetal, 38\% das sementes germinadas eram provenientes da posição inferior do terreno. Na pastagem, não foram observadas diferenças acentuadas na quantidade de sementes germinadas de graminóides e herbáceas-cipós, entre as posições do terreno, enquanto as arbustivas predominaram na posição inferior. Na floresta, na posição superior, representada pelo topo, a quantidade de sementes de graminóides foi mais elevada do que nas demais posições que se localizavam na encosta, possivelmente em razão da floresta no topo apresentar maior abertura de dossel e, conseqüentemente, facilitar o estabelecimento desse grupo de plantas. Porém as herbáceas-cipó e arbustivas predominaram na posição inferior, enquanto as sementes de arbóreas estavam distribuídas nas três posições do terreno. No plantio de eucalipto, não houve variação marcante no número de sementes de graminóides entre as posições do terreno, porém a quantidade de sementes germinadas de herbáceas-cipó decresceram substancialmente no sentido da posição inferior para a superior. Por outro lado, as sementes de arbustivas e de arbóreas foram mais elevadas nas posições superior e média do terreno, possivelmente em razão da maior proximidade da floresta, que se encontra acima do plantio de eucalipto.

A declividade do terreno em cada posição em que foi amostrado o banco de sementes pode estar afetando a quantidade de sementes no solo, especialmente em razão do escoamento superficial da água, favorecendo o transporte das sementes para as posições inferiores do terreno. Além do efeito de arrastamento das sementes pela água das chuvas, existe também o efeito da força gravitacional e a deposição das sementes em camadas mais profundas do solo.

O número de espécies do banco de sementes em pastagem no Rio Grande do Sul foi, também, menor nas encostas em comparação com as áreas baixas e outras porções do relevo (MAIA et al. 2003; MAIA et al. 2004). Borém e Oliveira-Filho (2002) verificaram que a freqüência, densidade e dominância das espécies arbóreas da vegetação adulta, em fragmento de Floresta Atlântica, diminuíram do terço inferior para o terço superior.

A proximidade da fonte de propágulos pode, também, estar influenciando positivamente o banco de sementes, favorecendo a regeneração natural. Borges e Engel (1993) observaram variação na composição do banco de sementes em plantio de eucalipto com o distanciamento do fragmento florestal. Castro et al. (2003) também observaram que o número de sementes germinadas do banco de sementes do solo de uma pastagem decresceu com o aumento da distância da fonte de sementes, constituída por uma mata de galeria, e resultado similar a esse estudo foi observado por Puerta (2002) na análise da regeneração arbórea em pastagens abandonadas em Manaus.

\section{CONCLUSÕES}

- O banco de sementes do solo estudado em áreas contíguas da pastagem degradada, plantio de eucalipto e floresta, em Paula Cândido (MG), apresentou um elevado número de sementes germinadas de graminóides e herbáceas, característico de ambientes perturbados, devendo ser considerado em planos de manejo que visem à regeneração natural dessas áreas.

- A composição florística do banco de sementes do solo variou com a cobertura vegetal e a posição de amostragem no relevo, indicando ser necessário que essas variáveis sejam consideradas na elaboração de planos para a recomposição da vegetação.

- A floresta de eucalipto estudada apresentou número de sementes germinadas de espécies arbustivas e arbóreas mais elevado do que a pastagem degradada. Esse resultado indica que o estabelecimento de plantios de florestas comerciais pode constituir uma forma de reduzir custos para a recomposição da vegetação natural em áreas de pastagens degradadas, uma vez que podem ser exploradas em um ou dois cortes, com posterior abandono da área para regeneração natural. 


\section{REFERÊNCIAS}

ARAÚJO, M. M.; LONGHI, S. J.; BARROS, P. L. C.; BRENA, D. A. Caracterização da chuva de sementes, banco de sementes do solo e banco de plântulas em floresta estacional decidual ripária, Cachoeira do Sul, RS, Brasil. Scientia Forestalis, Piracicaba, n. 66, p. 128-141, 2004.

ARAUJO, M. M.; OLIVEIRA, F. A.; VIEIRA, I. C. G.; BARROS, P. L. C.; LIMA, C. A. T. Densidade e composição florística do banco de sementes do solo de florestas sucessionais na região do baixo Rio Guamá, Amazônia Oriental. Scientia Forestalis, Piracicaba, n. 59, p. 115-130. 2001.

BAIDER, C.; TABARELLI, M.; MANTOVANI, W. O banco de sementes de um trecho de uma floresta atlântica montana (São Paulo - Brasil). Revista Brasileira de Biologia, Rio de Janeiro, v. 59, n. 2, p. 319328, 1999.

BAIDER, C.; TABARELLI, M.; MANTOVANI, W. The soil seed bank during Atlantic Forest regeneration in southeast Brazil. Revista Brasileira de Biologia, Rio de Janeiro, v. 61, n. 1, p. 35-44, 2001.

BATISTA NETO, J. P. Banco de sementes do solo de uma floresta estacional semidecidual, Viçosa, Minas Gerais. 85p. Dissertação (Mestrado em Ciência Florestal) - Universidade Federal de Viçosa, Viçosa, MG, 2005.

BERTONCINI, A. P.; RODRIGUES, R. R. Avaliação do banco de sementes em pastagens da terra indígena Araribá como subsídio à restauração florestal. In: CONGRESSO DE ECOLOGIA DO BRASIL, 4., 2003, Fortaleza. Anais ... Fortaleza: Editora da Universidade Federal do Ceará, 2003. v. 1, p. 493-495.

BORÉM, R. A. T.; OLIVEIRA-FILHO, A. T. Fitossociologia do estrato arbóreo em uma toposseqüência alterada de mata atlântica, no município de Silva Jardim-RJ, Brasil., Revista Árvore, Viçosa, MG, v. 26, n. 6, p. 727-742, 2002.

BORGES, K. H.; ENGEL, V. L. Influência de fragmentos de vegetação nativa na composição do banco de sementes de povoamentos implantados de eucaliptos. In: CONGRESSO FLORESTAL PANAMERICANO, 1.; CONGRESSO FLORESTAL BRASILEIRO, 7., 1993, Curitiba. Anais ... Curitiba: SBS/SBEF, 1993. p. 434-437.

BUDOWSKI, G. Distribution of tropical american rain Forest species of successional processes. Turrialba, San Jose, CR, v. 15, n. 1, p. 40-42, 1965.

CALEGARIO, N.; SOUZA, A. L.; MARANGON, L. C; SILVA, A. F. Parâmetros florísticos e fitossociológicos da regeneração natural de espécies arbóreas nativas no sub-bosque de povoamentos de Eucalyptus. Revista Árvore, Viçosa, MG, v. 17, n. 1, p. 16-29, 1993.

CASTRO, G. C.; NUNES, Y. R. F.; FAGUNDES, M. Banco de sementes do solo de uma área de transição entre mata de galeria e pastagem no município de Francisco Dumont, MG. In: CONGRESSO DE ECOLOGIA DO BRASIL, 4., 2003, Fortaleza. Anais ... Fortaleza: Editora da Universidade Federal do Ceará, 2003. v.1, p.507-509.

CAETANO, R. S. X., CHRISTOFFOLETI, P. J.; VICTORIA FILHO, R. "Banco" de sementes de plantas daninhas em pomar de laranjeira 'pera'. Scientia Agrícola, Piracicaba, v. 58, n. 3, p. 509-517, 2001.

FRANCO, B. K. S. Análise do banco de sementes e da regeneração natural em um trecho de floresta estacional semidecidual no Campus da Universidade Federal de Viçosa, MG. 72p. Dissertação (Mestrado em Ciência Florestal) - Universidade Federal de Viçosa, Viçosa, MG, 2005.

FUNDAÇÃO SOS MATA ATLÂNTICA. Evolução dos remanescentes florestais e ecossistemas associados do domínio da Mata Atlântica no período 1985-1990 - Relatório. 1993. São Paulo, 1993.

GOLDENBERGER, R.; VARASSIN, I. G. Sistemas reprodutivos de espécies de Melastomataceae da Serra do Japi, Jundiaí, São Paulo, Brasil. Revista Brasileira de Botânica, São Paulo, v. 24, n. 3, p. 283288, 2001. 
GROSS, K. L. A comparison of methods for estimating seed numbers in the soil. Journal of Ecology, Oxford, GB, v. 78, p. 1079-1093, 1990.

HIGUCHI, P. Dinâmica da regeneração natural da vegetação arbórea em um fragmento de floresta estacional semidecidual montana secundária, em Viçosa, MG. 107p. Dissertação (Mestrado em Ciência Florestal) - Universidade Federal de Viçosa, Viçosa, MG, 2003.

LACERDA, A. L. S.; VICTORIA FILHO, R. MENDONCA, C. G. Levantamento do banco de sementes em dois sistemas de manejo de solo irrigados por pivô central. Planta Daninha, Rio de Janeiro, v. 23, n. 1, p. 1-7, 2005.

LEAL FILHO, N. Caracterização do banco de sementes de três estádios de uma sucessão vegetal na Zona da Mata de Minas Gerais. 116p. Dissertação (Mestrado em Ciência Florestal) - Universidade Federal de Viçosa, Viçosa, MG, 1992.

LOUZADA, C. Composição florística e estrutura de vegetação arbórea em diferentes condições fisiográficas de um fragmento de floresta estacional semidecidual secundária, na Zona da Mata de Minas Gerais. 149p. Dissertação (Mestrado em Ciência Florestal) - Universidade Federal de Viçosa, Viçosa, MG, 2002.

LUGO, A. E. The apparent paradox of establishing species richness on degraded lands with tree monocultures. Forest Ecology and Management, Amsterdam, v. 99, p. 9-19, 1997.

MAIA, F. C.; MEDEIROS, R. B. de; PILLAR, V. de P.; CHOLLET, D.M.S.; OLMEDO, M.O.M. Composição, riqueza e padrão de variação do banco de sementes do solo em função da vegetação de um ecossistema de pastagem natural. Iheringia. Série, Botânica, Porto Alegre, v. 58, n. 1, p. 61-80, 2003.

MAIA, F. C.; MEDEIROS, R. B. de; PILLAR, V. de P.; FOCHT, T. Soil seed bank variation patterns according to environmental factors in a natural grassland. Revista Brasileira de Sementes, Brasília, v. 26, n. 2, p. 126-137, 2004.

NERI, A. V.; CAMPOS, E. P.; DUARTE, T. G.; MEIRA NETO, J. A. A., SILVA, A. F.; VALENTE, G. E. Regeneração de espécies nativas lenhosas sob plantio de Eucalyptus em área de Cerrado na Floresta Nacional de Paraopeba, MG, Brasil Acta Botânica Brasileira, São Paulo, v.19, n.2, p.369-376, 2005.

PEREIRA, R. A.; REIS, G. G.; REIS, M. G. F.; BRITES, R. S. Caracterização da paisagem, com ênfase em fragmentos florestais, do município de Viçosa, Minas Gerais. Revista Árvore, Viçosa, MG, v. 25, n. 3, p. 327-333, 2001.

PEZZOPANE, J. E. M. Caracterização microclimática, ecofisiológica e fitossociológica em uma floresta estacional semidecidual secundária, em Viçosa, MG. 255p. Tese (Doutorado em Ciência Florestal) - Universidade Federal de Viçosa, Viçosa, MG, 2001.

PUERTA, R. Regeneração arbórea em pastagens abandonadas na região de Manaus em função da distância da floresta contínua. Scientia Forestalis, Piracicaba n. 62, p. 32-39, 2002.

SILVA, A. F.; OLIVEIRA. R. V.; SANTOS, N. R. L.; PAULA, A. Composição florística e grupos ecológicos das espécies de um trecho de floresta semidecídua submontana da Fazenda São Geraldo, Viçosa-MG. Revista Árvore, Viçosa, MG, v. 27, n. 3, p. 311-319, 2003.

SILVA, C. T. da, REIS, G. G. dos, REIS, M. das G. F.; SILVA, E.; CHAVES, R. A. Avaliação temporal da florística arbórea de uma floresta secundária no município de Viçosa, Minas Gerais. Revista Árvore, Viçosa, MG, v. 28, n. 3, p. 429-441, 2004.

SOUZA, P. A.; VENTURIN, N.; GRIFFITH, J. J.; MARTINS, S. V. Efeito da sazonalidade da serapilheira sobre o banco de sementes de um fragmento florestal, visando seu uso na recuperação de áreas degradadas. Cerne, Lavras, v. 12, n. 1, p. 56-67, 2006

VOLL, E.; TORRES, E.; BRIGHENTI, A. M.; GAZZIERO, D. L. P. Dinâmica do banco de sementes de plantas daninhas sob diferentes sistemas de manejo de solo. Planta Daninha, Rio de Janeiro, v. 19, n. 2, p. 171-178, 2001. 